\title{
The Global Streamflow Indices and Metadata Archive (GSIM) - Part 2: Quality control, time-series indices and homogeneity assessment
}

\author{
Lukas Gudmundsson $^{1}$, Hong Xuan $\mathrm{Do}^{2}$, Michael Leonard ${ }^{2}$, and Seth Westra ${ }^{2}$ \\ ${ }^{1}$ Institute for Atmospheric and Climate Science, Department of Environmental Systems Science, \\ ETH Zurich, Universitaetstrasse 16, Zurich 8092, Switzerland \\ ${ }^{2}$ School of Civil, Environmental and Mining Engineering, University of Adelaide, Adelaide, Australia
}

Correspondence: Lukas Gudmundsson (lukas.gudmundsson@env.ethz.ch)

Received: 7 September 2017 - Discussion started: 20 September 2017

Revised: 9 March 2018 - Accepted: 16 March 2018 - Published: 17 April 2018

\begin{abstract}
This is Part 2 of a two-paper series presenting the Global Streamflow Indices and Metadata Archive (GSIM), which is a collection of daily streamflow observations at more than 30000 stations around the world. While Part 1 (Do et al., 2018a) describes the data collection process as well as the generation of auxiliary catchment data (e.g. catchment boundary, land cover, mean climate), Part 2 introduces a set of quality controlled time-series indices representing (i) the water balance, (ii) the seasonal cycle, (iii) low flows and (iv) floods. To this end we first consider the quality of individual daily records using a combination of quality flags from data providers and automated screening methods. Subsequently, streamflow time-series indices are computed for yearly, seasonal and monthly resolution. The paper provides a generalized assessment of the homogeneity of all generated streamflow time-series indices, which can be used to select time series that are suitable for a specific task. The newly generated global set of streamflow time-series indices is made freely available with an digital object identifier at https://doi.pangaea.de/10.1594/PANGAEA.887470 and is expected to foster global freshwater research, by acting as a ground truth for model validation or as a basis for assessing the role of human impacts on the terrestrial water cycle. It is hoped that a renewed interest in streamflow data at the global scale will foster efforts in the systematic assessment of data quality and provide momentum to overcome administrative barriers that lead to inconsistencies in global collections of relevant hydrological observations.
\end{abstract}

1

Although terrestrial freshwater is an essential component of the Earth system and a prerequisite for societal development, the availability of relevant in situ observations at the global scale has been limited. Until now, most relevant in situ observations have been held by national and regional authorities, and despite their best efforts, international data centres only have access to a small subset of the full observed record (Do et al., 2018a). This situation stands in contrast to the fact that monitoring data are increasingly being made publicly available through regional and national authorities (Do et al., 2018a). In this paper series, we present an international collection of river and streamflow observations that covers more than 30000 stations around the globe, highlighting the fact that these are among the best monitored variables of the terrestrial water cycle (Fekete et al., 2012, 2015; Gudmundsson and Seneviratne, 2015; Hannah et al., 2011). Part 1 of the paper series (Do et al., 2018a) documents the data-collection process together with a meta-database that allows users to recreate the collection from the original data sources. In addition, Part 1 of this paper series also presents auxiliary data including catchment boundaries delineated from global digital elevation models as well as selected properties (e.g. land cover, climate) of these catchments.

While the data collection outlined in Part 1 (Do et al., 2018a) increases the spatial and temporal availability of streamflow records at the global scale, it is important to also 
consider the quality of the data. This is especially relevant for this merged data product combining information from several databases, which might have been set up with different objectives. Furthermore, data contained in individual databases may stem from different sources, often with unknown quality control procedures. In addition, changes in instrumentation as well as human impacts such as stream straightening or flow regulations can have pronounced effects on the observed record. Establishing a database of quality controlled streamflow observations is therefore essential for many applications, including e.g. the need to evaluate the increasing number of continental- and global-scale hydrological and land-surface models that have emerged in recent decades (Beck et al., 2017; Gudmundsson et al., 2012a, b; Haddeland et al., 2011; Zaitchik et al., 2010) and the assessment of human impacts on the terrestrial water cycle (Alkama et al., 2013; Barnett et al., 2008; Destouni et al., 2013; Gudmundsson et al., 2017; Hegerl et al., 2015; Hidalgo et al., 2009; Jaramillo and Destouni, 2015; Oliveira et al., 2011). While there have been significant efforts in the climatological community to share and standardize transnational weather observations as well as derivative data products (Alexander et al., 2006; Becker et al., 2013; Dee et al., 2011; Harris et al., 2014; Haylock et al., 2008; Poli et al., 2016), the hydrological community has traditionally been reticent to adopt regional or global approaches, instead focussing predominantly on the catchment scale. A more concerted and coordinated effort to understand the quality of streamflow observations across the globe provides significant opportunities for fostering hydrological research in support of understanding of global water budgets. This paper initiates the process of evaluating, analysing and documenting the quality of observed streamflow time series, providing a method for increasing the reliability and ongoing value of the database. To do so, this paper expands on previous research (Gudmundsson and Seneviratne, 2016) and applies a set of transparent and reproducible methods to evaluate the quality of the considered records.

One limitation of the newly assembled collection of daily river flow and streamflow time series is that publication of unprocessed daily values is restricted for some of the original data sources. To nevertheless be able to publish relevant information on observational streamflow, we therefore present here processed data in the form of time-series indices that capture essential aspects of (i) the water balance, (ii) seasonality, (iii) low flows and (iv) floods. The approach of publishing time-series indices instead of raw daily values is adapted from the CCl/WCRP/JCOMM Expert Team on Climate Change Detection and Indices (ETCCDI) (https: //www.wcrp-climate.org/data-etccdi), which has developed this approach to make relevant climate information publicly available in cases where access to raw daily values is restricted. The ETCCDI has focussed on indices characterizing changes in extreme precipitation and temperature, based on a core collection of indices proposed by Frich et al. (2002).
Both Klein Tank et al. (2009) and Zhang et al. (2011) provide additional background on the usage and computation of the ETCCDI indices. Klein Tank et al. (2009) also provide guidelines for quality control of the raw daily input data, index computation and assessment of time-series homogeneity.

The use of time-series indices for characterizing the temporal evolution of selected river flow characteristics is also common practice in the hydrological literature. Typically used time-series indices include mean annual flows (e.g. Kumar et al., 2009; Milly et al., 2005; Small et al., 2006; Stahl et al., 2010, 2012), indices that can be used to characterize changes in the seasonal cycle (e.g. Blöschl et al., 2017; Cunderlik and Ouarda, 2009; Ehsanzadeh and Adamowski, 2010; Hidalgo et al., 2009; Moore et al., 2007; Rauscher et al., 2008; Regonda et al., 2005; Stewart et al., 2005), time series of annual percentiles (e.g. Gudmundsson et al., 2011; Lins and Slack, 1999; Zhang et al., 2001), flood indices (e.g. Blöschl et al., 2017; Hodgkins et al., 2017; Kumar et al., 2009; Kundzewicz et al., 2005; Lins and Slack, 1999; McCabe and Wolock, 2002; Small et al., 2006; Svensson et al., 2005; Zhang et al., 2001) and low-flow indicators (e.g. Hisdal et al., 2001; Lins and Slack, 1999; McCabe and Wolock, 2002; Small et al., 2006; Stahl et al., 2010, 2012; Svensson et al., 2005; Tallaksen et al., 1997; Zhang et al., 2001).

In addition, several studies have focussed on collections of hydrological signatures (or flow characteristics) that are designed to summarize long-term properties of observed river flow and streamflow (e.g. 2013; Beck et al., 2015; Olden and Poff, 2003; Sawicz et al., 2011, 2014; Westerberg et al., 2016). These hydrological signatures include e.g. mean annual flow, flow percentiles, characteristics of the flow duration curves, indications of seasonality and the base flow index. These signatures are typically derived from all daily values in a long time window (e.g. the base flow index computed from all daily values from 1985 to 2010). This is an important structural difference if compared to time-series indices, which are typically computed every year, every season or every month (e.g. time series of annual maxima) and thus also allow for an assessment of changing hydrological conditions over time.

The following sections build upon these efforts and present a collection of quality controlled river and streamflow timeseries indices. To do so, we first introduce an approach to check the quality of individual daily observations using a combination of information provided with the original data and data-driven procedures. Subsequently we present a collection of time-series indices that can be computed for yearly, seasonal and monthly resolution. An assessment of the statistical homogeneity of the newly derived indices is provided to allow users to filter the published data according to their own eligibility criteria. Given that each application may warrant a different assessment of the trade-off between the quantity and quality of available data, the presented collection of streamflow time-series indices has sought to avoid predefined eligibility criteria (such as predefining a base period 
Table 1. Quality flags of daily values of all databases that enter the GSIM collection (see Do et al., 2018a).

\begin{tabular}{|c|c|}
\hline Database & Quality code \\
\hline GRDB & $\begin{array}{l}\text { Not recommended by data provider. There are four flags: } \\
-999 \text { - missing data, no correction } \\
1 \text { - corrected data, no method specified } \\
99 \text { - usage not recommended by the provider } \\
900 \text { - calculated from daily water level } \\
\text { Note: in recent updates GRDC does not provide quality flags. }\end{array}$ \\
\hline EWA & Not recommended by data provider (similar to GRDB) \\
\hline ARCTICNET & Quality flag not provided \\
\hline GAME & Quality flag not provided \\
\hline CHDP & Quality flag not provided \\
\hline USGS & $\begin{array}{l}\text { Flags were provided for each data point. There are four categories: } \\
\text { A: value has been validated to be published } \\
\text { A:e: value was estimated and validated to be published } \\
\text { P and P:e: Provisional data }\end{array}$ \\
\hline BOM & $\begin{array}{l}\text { Flags were provided for each data point. There are five categories documented: } \\
\text { A (flag 10): best available data } \\
\text { B (flag 90): compromised to represent the parameter } \\
\text { C (flag 110): estimated value } \\
\text { E (flag 140): quality is not known } \\
\text { F (flag 210): poor quality or missing } \\
\text { Flag "-1" also presents to indicate missing value }\end{array}$ \\
\hline HYDAT & $\begin{array}{l}\text { Quality flags were only provided for some data points. There are five categories documented: } \\
\text { A: Partial Day (numeric value 1) } \\
\text { B: Ice Conditions (numeric value } 2 \text { ) } \\
\text { D: Dry (numeric value 3) } \\
\text { E: Estimated (numeric value 4) } \\
\text { S: Sample(s) collected this day (numeric value 5) }\end{array}$ \\
\hline WRIS & Qc flag not provided \\
\hline ANA & $\begin{array}{l}\text { Quality flags were only provided for some data points. Flags were described in Portuguese. } \\
\text { Below are the authors' interpretation. } \\
\text { 0: No description } \\
\text { 1: Real measurement } \\
\text { 2: Estimated } \\
\text { 3: Doubtful } \\
\text { 4: Dry }\end{array}$ \\
\hline MLIT & Quality flag not provided \\
\hline AFD & Quality flag not provided \\
\hline
\end{tabular}

or presupposing only high-quality sites). The paper closes with an open invitation to the hydrological and Earth science communities on how to best facilitate activities that might lead to sustained collation, curation and improvement of global streamflow data.

\section{Quality control (QC) of daily values}

\subsection{Strategy for $\mathrm{QC}$ of daily values}

As the considered data stem from several sources, some of which have a complex history, it is difficult to a priori judge the quality of individual records. Ideally, each of the considered series would be accompanied by detailed information on the station properties (e.g. information on sensors or the design of the gauging weir) and on the credibility of indi- 
Table 2. Translation of daily quality control (QC) flags of the original databases (Table 1) to standardized values prior to the calculation of indices. Note that the Global Runoff Data Centre advises not to consider the QC flags in the GRDB and EWA files. Note also that some databases (HYDAT, ANA) do not provide QC flags for all daily data.

\begin{tabular}{lllll}
\hline Dataset & $\begin{array}{l}\text { QC flag } \\
\text { not provided }\end{array}$ & $\begin{array}{l}\text { QC flags are not recommended } \\
\text { by data provider }\end{array}$ & Reliable & Suspect \\
\hline GRDB & - & All data points & - & - \\
EWA & - & All data points & - & - \\
ARCTICNET & All data points & - & - & - \\
GAME & All data points & - & - & - \\
CHDP & All data points & - & - & - \\
USGS & - & - & "A" and “A:e" (approved data) & "P" and "P:e" data (provisional data) \\
BOM & - & A (table below) & B, C, D, F (table below) \\
HYDAT & Other data points & - & B, D, S & A, E \\
WRIS & All data points & - & - & - \\
ANA & 0, no value & - & 1,4 & 2,3 \\
MLIT & All data points & - & - & - \\
AFD & All data points & - & - & - \\
\hline
\end{tabular}

vidual daily values. However, this information is often not available or difficult to access and only some of the original data sources provide daily quality flags (Table 1 ). In addition, the large number of languages involved and the sheer quantity of gauging stations render a detailed manual assessment unfeasible. Nevertheless, it is essential to apprise the quality of individual observations prior to any assessment. As some of the considered time series come with daily quality flags (usually based on simple plausibility checks), while others do not, the two cases are treated separately.

\subsection{Quality control of daily values if reliable flags are provided}

As noted in Do et al. (2018a), some of the considered databases provide quality control (QC) flags for daily values that distinguish between reliable and suspect observations (Table 1). To allow for a combined assessment, the original QC flags were translated into a common set that distinguishes suspect from reliable values (Table 2). This step is necessary for consistency, since some databases provide a variety of QC flags to indicate suspect cases, but neither the same flags nor the level of fidelity are available across all databases. Regarding the Global Runoff Data Centre (GRDC), while QC flags are available in the EWA and GRDB files entering the presented collection, the GRDC advised not to use them. In these cases, the time series are treated as if no QC flags were provided. Note also that the GRDC has discontinued QC flagging in the latest version of the data. Some databases do not provide QC flags for every time step (Table 2); in these cases time steps without original QC flags were assumed to be reliable as long as at least one time step was flagged in the respective time series.

\subsection{Quality control of daily values if no reliable flags are available}

For original time-series files for which no QC flags are available or for which there is advice against using available QC flags by the data providers (GRDB and EWA), automated techniques can be used to classify the reliability of individual daily data points using simple and reproducible tests focussing on the plausibility of individual values. The following three criteria are based on a previously used procedure (Gudmundsson and Seneviratne, 2016), were developed on the basis of techniques described in Reek et al. (1992) and the ECA \& D Project Team and Royal Netherlands Meteorological Institute (2013; later referred to as EAC\&D13), and were further refined using suggestions on outlier detection for index calculation by Klein Tank et al. (2009):

1. Days for which $Q<0$ are flagged as suspect, where $Q$ denotes a daily streamflow value. The rationale underlying this rule is that streamflow values smaller than zero are non-physical (Gudmundsson and Seneviratne, 2016).

2. Daily values with more than 10 consecutive equal values larger than zero are flagged as suspect. This rule is motivated by the fact that many days with consecutive streamflow values often occur due to instrument failure (e.g. damaged sensors, ice jams) or flow regulations. The threshold of 10 days is a compromise chosen to account for the possibility that consecutive equal observations may reflect the truth e.g. if day-to-day fluctuations are below the sensitivity of the employed sensor (Gudmundsson and Seneviratne, 2016).

3. Based on a previously suggested approach for evaluating temperature series (Klein Tank et al., 2009), daily streamflow values are declared as outliers if values of $\log (Q+0.01)$ are larger or smaller than the mean value 


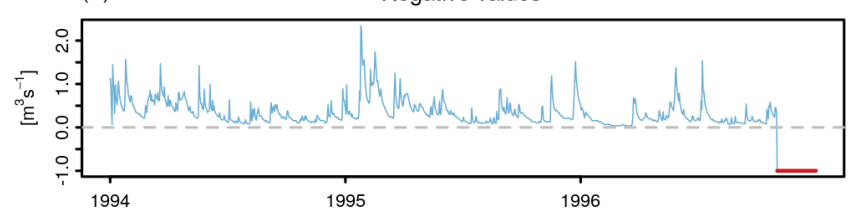

(b)

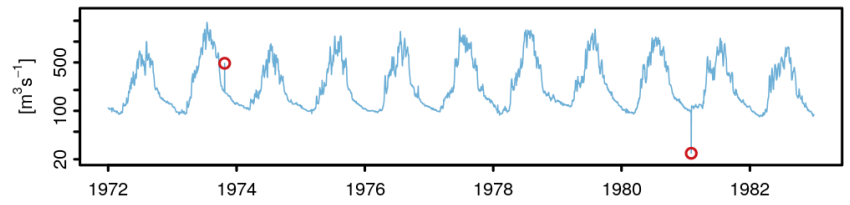

(c)

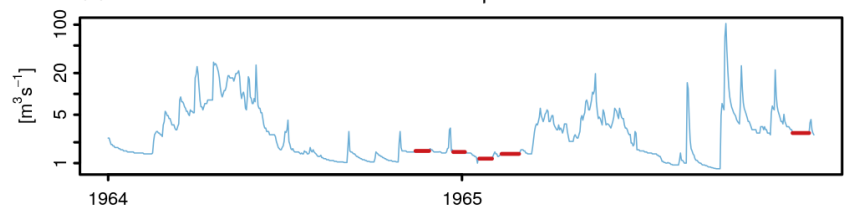

Figure 1. Three example time series illustrating issues detected by the three daily quality control criteria (highlighted in red). The first panel shows negative values at the end of the time series of Rohr at Rohrhardsberg, Germany. The second panel shows two outliers detected in the time series of Vakhsh at Gram, Tajikistan. The third panel shows instances of more than 10 consecutive equal values found in the time series of Tanara at Ponte di Nava, Italy. Note that all time series were trimmed for visualization purposes. Note also the logarithmic axis in panels two and three.

of $\log (Q+0.01)$ plus or minus 6 times the standard deviation of $\log (Q+0.01)$ computed for that calendar day for the entire length of the series. The mean and standard deviation are computed for a 5-day window centred on the calendar day to ensure that a sufficient amount of data is considered. The log-transformation is used to account for the skewness of the distribution of daily streamflow values and 0.01 was added because the logarithm of zero is undefined. Outliers are flagged as suspect. The rationale underlying this rule is that unusually large or small values are often associated with observational issues. The 6 standard-deviation threshold is a compromise, aiming at screening out outliers that could come from instrument malfunction, while not flagging extreme floods or low flows.

An example of the outcome of this automated quality control of daily observations is shown in Fig. 1, which displays daily streamflow observations at three locations and highlights time steps that did not pass the three above-mentioned criteria. Note that the outlier detection (middle panel) did not screen out extreme floods or low flows, but only values that were unusually large or small for the respective time of the year, where one case involves a spurious large flow and the other a spurious small flow.

\section{Streamflow indices}

\subsection{General considerations, design rules and reliability}

\subsubsection{General considerations}

Table 3 describes a set of streamflow time-series indices that are designed to facilitate the analysis of (i) changes in the regional water balance, (ii) changes in the seasonal cycle, (iii) floods, and (iv) low flows. Many of the considered indices have been previously used in the scientific literature and Table 4 presents, wherever possible, a selection of relevant references and additional information. Note also that index selection was limited to those that can be computed without a base period, which excludes many; examples include "the number of days in a year, or season, for which daily values exceed a time-of-year-dependent threshold" (Zhang et al., 2005), drought deficit volumes (Loon and Anne, 2015; Tallaksen et al., 1997) and anomalies with respect to a climatological normal (McKee et al., 1993; Shukla and Wood, 2008). There are two reasons for excluding these indices: first, regional differences in temporal coverage hinder an unambiguous identification of a common base period that can be used around the globe. Second, it is now well established that indices that depend on a base period are prone to inhomogeneities if the base period is shorter than the considered series (Sippel et al., 2015; Zhang et al., 2005). Although both analytical (Sippel et al., 2015) and non-parametric (Zhang et al., 2005) solutions exist to mitigate this problem, we chose not to include indices that require a base period. This is because the available solutions either depend on strong normality assumptions (Sippel et al., 2015) or are computationally intensive (Zhang et al., 2005), which implies that the timeseries indices cannot be easily extended when new data become available. Finally, it is noteworthy to mention that indices are easier to update when they do not have a base period, as they can be computed without knowledge of previous values.

\subsubsection{Design rules for index calculation}

The design rules for calculating time-series indices closely follow the recommendations of ECA\&D13. Before index calculation, all daily values that are flagged as suspect by the daily QC procedure are set to missing, and indices are computed using the remaining data points. All indices are computed on yearly time steps, while some indices are also computed with seasonal and monthly resolution. Seasons are defined as December-January-February (DJF), March-April-May (MAM), June-July-August (JJA) and September-October-November (SON). The reason for not computing all indices for seasonal and monthly resolutions is related either to the fact that some indices are only defined on annual timescales, or to the amount of data required for reliable computation. All considered indices are described in Tables 3 and 4. 
Table 3. Definition of time-series indices contributing to the GSIM archive. Abbrev. Indicates the abbreviation of the index name used throughout this paper as well as in the database. Resol. indicates the time resolution for which the index is computed, which can take values of Y (yearly), seasonal (S) and monthly (M).

\begin{tabular}{|c|c|c|c|c|}
\hline Title & Abbrev. & Units & Resol. & Definition \\
\hline Mean daily streamflow & MEAN & $\left(\mathrm{m}^{3} \mathrm{~s}^{-1}\right)$ & $\mathrm{Y}, \mathrm{S}, \mathrm{M}$ & Arithmetic mean of daily streamflow. \\
\hline $\begin{array}{l}\text { Standard deviation of daily } \\
\text { streamflow }\end{array}$ & SD & $\left(\mathrm{m}^{3} \mathrm{~s}^{-1}\right)$ & $\mathrm{Y}, \mathrm{S}, \mathrm{M}$ & Standard deviation of daily streamflow. \\
\hline $\begin{array}{l}\text { Coefficient of variation of } \\
\text { daily streamflow }\end{array}$ & $\mathrm{CV}$ & $(-)$ & $\mathrm{Y}, \mathrm{S}, \mathrm{M}$ & $\begin{array}{l}\text { Standard deviation of daily streamflow divided by the mean daily stream- } \\
\text { flow (SD/MEAN). }\end{array}$ \\
\hline $\begin{array}{l}\text { Interquartile range of daily } \\
\text { streamflow }\end{array}$ & IQR & $\left(\mathrm{m}^{3} \mathrm{~s}^{-1}\right)$ & $\mathrm{Y}, \mathrm{S}, \mathrm{M}$ & 75th-25th percentile of daily streamflow. \\
\hline $\begin{array}{l}\text { Minimum daily stream- } \\
\text { flow }\end{array}$ & MIN & $\left(\mathrm{m}^{3} \mathrm{~s}^{-1}\right)$ & $\mathrm{Y}, \mathrm{S}, \mathrm{M}$ & Minimum value of daily streamflow. \\
\hline $\begin{array}{l}\text { Maximum daily stream- } \\
\text { flow }\end{array}$ & MAX & $\left(\mathrm{m}^{3} \mathrm{~s}^{-1}\right)$ & $\mathrm{Y}, \mathrm{S}, \mathrm{M}$ & Maximum value of daily streamflow. \\
\hline $\begin{array}{l}\text { Minimum 7-day mean } \\
\text { streamflow }\end{array}$ & MIN7 & $\left(\mathrm{m}^{3} \mathrm{~s}^{-1}\right)$ & $\mathrm{Y}, \mathrm{S}, \mathrm{M}$ & $\begin{array}{l}\text { Minimum 7-day arithmetic mean streamflow. For computation, the com- } \\
\text { plete daily time series are first smoothed with a backward looking moving } \\
\text { average with a 7-day window. Subsequently, the minimum value for each } \\
\text { yearly, seasonal or monthly period is determined. }\end{array}$ \\
\hline
\end{tabular}

\begin{tabular}{|c|c|c|c|c|c|c|}
\hline $\begin{array}{l}\text { Maximum } \\
\text { streamflow }\end{array}$ & 7-day & mean & MAX7 & $\left(\mathrm{m}^{3} \mathrm{~s}^{-1}\right)$ & $\mathrm{Y}, \mathrm{S}, \mathrm{M}$ & $\begin{array}{l}\text { Maximum 7-day arithmetic mean streamflow. For computation, the com- } \\
\text { plete daily time series are first smoothed with a backward looking moving } \\
\text { average with a 7-day window. Subsequently, the maximum value for each } \\
\text { yearly, seasonal or monthly period is determined. }\end{array}$ \\
\hline
\end{tabular}

10th, 20th, 30th, 40th, P10, P20, $\left(\mathrm{m}^{3} \mathrm{~s}^{-1}\right) \quad \mathrm{Y}, \mathrm{S} \quad$ Percentile values of daily streamflow computed for each yearly and seasonal
50th, 60th, 70th, 80th and P30, P40, period, where low percentiles (e.g. 10th percentile) correspond to low flows. 90th percentiles of daily P50, P60, streamflow P70, P80, P90

\begin{tabular}{|c|c|c|c|c|}
\hline Centre timing & $\mathrm{CT}$ & (doy) & $\mathrm{Y}$ & $\begin{array}{l}\text { The day of the year (doy) at which } 50 \% \text { of the annual flow is reached. The } \\
\text { index is computed for calendar years, where } 1 \text { denotes } 1 \text { January. }\end{array}$ \\
\hline $\begin{array}{l}\text { Day of minimum stream- } \\
\text { flow }\end{array}$ & DOYMIN & (doy) & $\mathrm{Y}$ & $\begin{array}{l}\text { The day of the year (doy) at which the minimum flow occurred, where } 1 \\
\text { denotes } 1 \text { January. The maximum value is } 365 \text { for normal years and } 366 \text { for } \\
\text { leap years. }\end{array}$ \\
\hline $\begin{array}{l}\text { Day of maximum stream- } \\
\text { flow }\end{array}$ & DOYMAX & (doy) & $\mathrm{Y}$ & $\begin{array}{l}\text { The day of the year (doy) at which the maximum flow occurred, where } 1 \\
\text { denotes } 1 \text { January. The maximum value is } 365 \text { for normal years and } 366 \text { for } \\
\text { leap years. }\end{array}$ \\
\hline $\begin{array}{l}\text { Day of minimum } 7 \text {-day } \\
\text { mean streamflow }\end{array}$ & DOYMIN7 & (doy) & $\mathrm{Y}$ & $\begin{array}{l}\text { Day of the year (doy) at which the minimum 7-day arithmetic mean stream- } \\
\text { flow occurred, where } 1 \text { denotes } 1 \text { January. The maximum value is } 365 \text { for } \\
\text { normal years and } 366 \text { for leap years. For computation, the daily time series } \\
\text { is first smoothed using a backward looking moving average with a } 7 \text {-day } \\
\text { window length. Subsequently, the day of the minimum of each year is de- } \\
\text { termined. }\end{array}$ \\
\hline
\end{tabular}

\begin{tabular}{|c|c|c|c|c|}
\hline $\begin{array}{l}\text { Day of maximum 7-day } \\
\text { mean streamflow }\end{array}$ & DOYMAX7 & (doy) & $\mathrm{Y}$ & $\begin{array}{l}\text { Day of the year (doy) at which the maximum 7-day arithmetic mean stream- } \\
\text { flow occurred, where } 1 \text { denotes } 1 \text { January. The maximum value is } 365 \text { for } \\
\text { normal years and } 366 \text { for leap years. For computation, the daily time series } \\
\text { is first smoothed using a backward looking moving average with a } 7 \text {-day } \\
\text { window length. Subsequently, the Julian day of the maximum of each year } \\
\text { is determined. }\end{array}$ \\
\hline
\end{tabular}

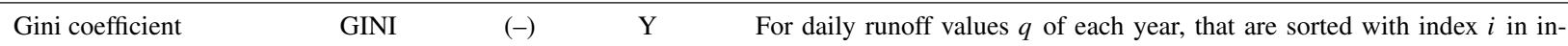
creasing order such that $q_{i} \leq q_{i+1}$ GINI is defined as $\frac{1}{n}\left(n+1-2\left(\frac{\sum_{i=1}^{n}(n+1-1) q_{i}}{\sum_{i=1}^{n} q_{i}}\right)\right)$, where $n$ is the number data points available for that year. The Gini coefficient ranges from 0 to 1 . Values of 0 indicate uniform distribution of flows throughout the time period (i.e. year), whereas values close to 1 indicate that all the flows occur on a single day. 
Table 4. Commentary and literature supporting the GSIM indices.

\begin{tabular}{|c|c|}
\hline Abbrev. & Commentary \\
\hline MEAN & $\begin{array}{l}\text { Mean daily streamflow is a commonly used water-balance measure and often used as a proxy for renewable freshwater } \\
\text { resources (Oki and Kanae, 2006; Shiklomanov et al., 2004; Vörösmarty et al., 2000). Observed time series of mean } \\
\text { yearly or monthly streamflow has e.g. been subject to trend analysis at regional to continental scales (e.g. Kumar et al., } \\
\text { 2009; Lettenmaier et al., 1994; Lins and Slack, 1999; Milly et al., 2005; Small et al., 2006; Stahl et al., 2010, 2012). }\end{array}$ \\
\hline
\end{tabular}

SD The standard deviation of daily streamflow provides information on the total variability for each yearly, seasonal and monthly time step. This index therefore includes information related to floods and low flows as well as the amplitude of the annual cycle (yearly only). We are not aware of any study analysing time series of the standard deviation of daily streamflow.

$\mathrm{CV} \quad$ The coefficient of variation of daily streamflow is a relative measure of daily variability. In contrast to $\mathrm{SD}, \mathrm{CV}$ is independent of the mean flow and does hence allow for an isolated assessment of day-to-day streamflow variability. We are not aware of any study analysing time series of the coefficient of variation of daily streamflow.

IQR The inter quartile range is a measure of day-to-day streamflow variability. Through its definition as the difference between the 75th and 25th percentiles, the IQR provides information on the width of the centre of the distribution and is less sensitive to extreme outliers than SD or CV. We are not aware of any study analysing time series of the standard deviation of daily streamflow.

MIN Minimum daily streamflow is a regularly used low-flow indicator. Especially the yearly minimum has been used widely as it is an easy to interpret measure and lends itself to analysis in the framework of the generalized extreme value distribution (Tallaksen and van Lanen, 2004). Annual minimum streamflow series are also commonly subject to largescale trend analysis (Kumar et al., 2009; Lins and Slack, 1999; McCabe and Wolock, 2002; Zhang et al., 2001).

MAX Maximum daily streamflow is a widely used indicator for high flows and floods. Especially annual maximum time series are regularly considered as they allow for a straightforward interpretation and can easily be analysed through the generalized extreme value distribution (Katz et al., 2002). Time series of annual maximum streamflow have been subject to regional and global trend assessments (e.g. Do et al., 2017; Hall et al., 2015; Kumar et al., 2009; Kundzewicz et al., 2005; Lins and Slack, 1999; McCabe and Wolock, 2002; Small et al., 2006; Zhang et al., 2001).

MIN7 Time series of minimum 7-day mean streamflow have been repeatedly used as a low-flow and drought metric. Through the smoothing operation, MIN7 is less sensitive to small day-to-day fluctuations, but focusses on sustained periods with limited water availability. MIN7 time series have e.g. been subject to large scale trend assessments (Kumar et al., 2009; Small et al., 2006; Stahl et al., 2010; Svensson et al., 2005).

MAX7 Time series of 7-day mean maximum streamflow do not focus on the highest water levels ever recorded, but rather on sustained periods of very high flow. Time series of MAX7 have e.g. been used to assess streamflow trends in India (Kumar et al., 2009; Stahl et al., 2012).

P10, P20, Percentiles of daily streamflow provide together with MIN and MAX an approximation of the empirical cumulative $\mathrm{P} 30, \quad \mathrm{P} 40, \quad$ distribution function (ECDF) of daily streamflow for each considered seasonal or yearly time period. These indices are P50, P60, not provided on monthly resolution, as it appears to be excessive to compute percentiles in $10 \%$ steps based on 28 to 31 P70, P80, daily values. Note also that an alternative definition of the ECDF is also referred to as the flow-duration curve (FDC) in P90 the hydrological literature. The difference between the ECDF and the FDC is that the FDC uses an inverse definition of percentiles (exceedance frequencies), such that high values correspond to low flows (Tallaksen and van Lanen, 2004; Vogel and Fennessey, 1994). Besides approximations of the ECDF, the percentile series can be used to characterize "moderate extremes" (Zhang et al., 2011), i.e. very high or very low values that can occur several times each year and are hence more robust to quantify. Sets of annual percentile series have for example been used to investigate regional low- and high-flow dynamics in Europe (Gudmundsson et al., 2011) and have been subject to regional-scale trend assessments (Lins and Slack, 1999; McCabe and Wolock, 2002; Zhang et al., 2001).

CT The centre timing is an index that is sensitive to changes in the seasonal cycle. Lower values indicate that more than half of the annual discharge has occurred earlier in the year. That means, that values smaller or equal than 182 would correspond to a year for with at least half of the streamflow volume has occurred in the first half of the year. Note that CT is usually defined for hydrological years in the literature and that the precise definition of CT can vary between studies (Hidalgo et al., 2009; Moore et al., 2007; Rauscher et al., 2008; Regonda et al., 2005; Stewart et al., 2005). Here we compute CT for calendar years to ensure consistency with the remaining indices and because the definition of the hydrological year depends on local climate conditions. Time series of CT have been used to assess changes in the timing of the seasonal cycle of streamflow in several regional studies (Hidalgo et al., 2009; Moore et al., 2007; Rauscher et al., 2008; Regonda et al., 2005; Stewart et al., 2005).

DOYMIN The timing of annual minimum flow can provide valuable information on the processes underlying low flows. For example, in snowy regions, the minimum flow often occurs in the winter months, whereas in other regions minimum flows occur in the season with low precipitation and large atmospheric water demand. We are not aware of any study that is explicitly analysing time series of DOYMIN. 
Table 4. Continued.

\begin{tabular}{ll}
\hline Abbrev. & Commentary \\
\hline DOYMAX & $\begin{array}{l}\text { The timing of annual maximum streamflow can be a valuable indicator for the flood generating processes. In cold } \\
\text { regions annual, maximum flow is often associated with snowmelt, while in other regions it may be associated with } \\
\text { intense convective precipitation during the warm season or soil moisture. Time series of DOYMAX have for example } \\
\text { been used to assess trends in the timing of floods in Europe (Blöschl et al., 2017) and Canada (Cunderlik and Ouarda, } \\
\text { 2009). }\end{array}$ \\
\hline DOYMIN7 & $\begin{array}{l}\text { Overall the interpretation of DOYMIN7 is analogous to the interpretation of DOYMIN. Note, however, that DOXMIN7 } \\
\text { is representative of a 7-day period of sustained low flows and is less sensitive to outliers. We are not aware of any study } \\
\text { that is explicitly analysing time series of DOYMIN. }\end{array}$ \\
\hline DOYMAX7 & $\begin{array}{l}\text { Generally, the interpretation of DOYMAX7 is analoguous to the interpretation of DOYMAX, although DOYMAX7 } \\
\text { represents a 1-week period of sustained high flows and is less sensitive to outliers. We are not aware of any study that } \\
\text { is explicitly analysing time series of DOYMAX7. }\end{array}$ \\
\hline GINI & $\begin{array}{l}\text { The Gini coefficient is a metric that was originally established in economic sciences as a measure of economic inequality } \\
\text { (Ceriani and Verme, 2012). It is a measure of dispersion that is not dependent on the absolute value of the variable under } \\
\text { consideration and can be interpreted as a measure of the variability implied by the flow duration curve. It is therefore, } \\
\text { like the CV, a relative variability measure that can easily be compared among different regions. Although we are not } \\
\text { aware of any study investigating annual GINI time series derived from streamflow, relevant applications to observed } \\
\text { precipitation (Rajah et al., 2014) and global hydrological model output (Masaki et al., 2014) are emerging. }\end{array}$ \\
\hline
\end{tabular}

\subsubsection{Reliability of index values}

Not all daily time steps have observations, and some daily observations have been flagged as suspect and were therefore removed. Consequently yearly, seasonal and monthly index values are not equally reliable. To allow users to judge the reliability of index values at individual time steps, the number of daily values used for index calculation at each time step is provided. Based on the recommendations of ECA\&D13, the following rules for daily data availability can be applied to identify reliable index values.

1. Index values at a yearly time step are reliable if at least 350 daily observations are declared reliable.

2. Index values at a seasonal time step are reliable if at least 85 daily observations are declared reliable.

3. Index values at a monthly time step are reliable if at least 25 daily observations are declared reliable.

Note, however, that these are very conservative rules which may be relaxed depending on the needs of specific applications.

\subsection{Example time series}

To provide a first impression of the considered indices, Fig. 2 shows all indices at annual resolution for Wiese at Zell, located in south-western Germany. In addition, Fig. 3 shows the MEAN at monthly, seasonal and yearly resolutions of the same river.

\subsection{Temporal coverage of yearly, seasonal and annual indices}

Figure 4a displays the number of years covered by all considered time series, highlighting both large variations in station density and time-series length, which is consistent with the availability of the original daily time series (Do et al., 2018a). To better appraise regional differences in temporal coverage, Fig. $4 \mathrm{~b}$ shows the distribution of the number of years that are typically available for each station for major continental regions. The median time-series length is longest for North America and Europe and shortest for Oceania and Asia. The above-mentioned daily quality control (Sect. 2) as well as ECA\&D13 criteria for judging the reliability of yearly, seasonal or monthly index values (Sect. 3.1.3) imply that the space-time coverage of the index data is not equal to the coverage of the original daily time series. Figure $4 \mathrm{c}$ shows the distribution of the fraction of time steps that were classified as reliable for the considered continental regions and for yearly, seasonal and monthly resolutions. Overall the figure highlights that the fraction of reliable time steps is largest for the Americas, Europe and Asia, while it is lowest for Oceania and Africa. Furthermore, it should be noted that the fraction of reliable time steps is lowest for yearly indices. This is related to the fact that full years are deemed unreliable when fewer than 350 valid observations are used for computation (following the ECA\&D13 rules). Note however that the relatively strict ECA\&D13 rules can be relaxed and should be adapted depending on user needs. 


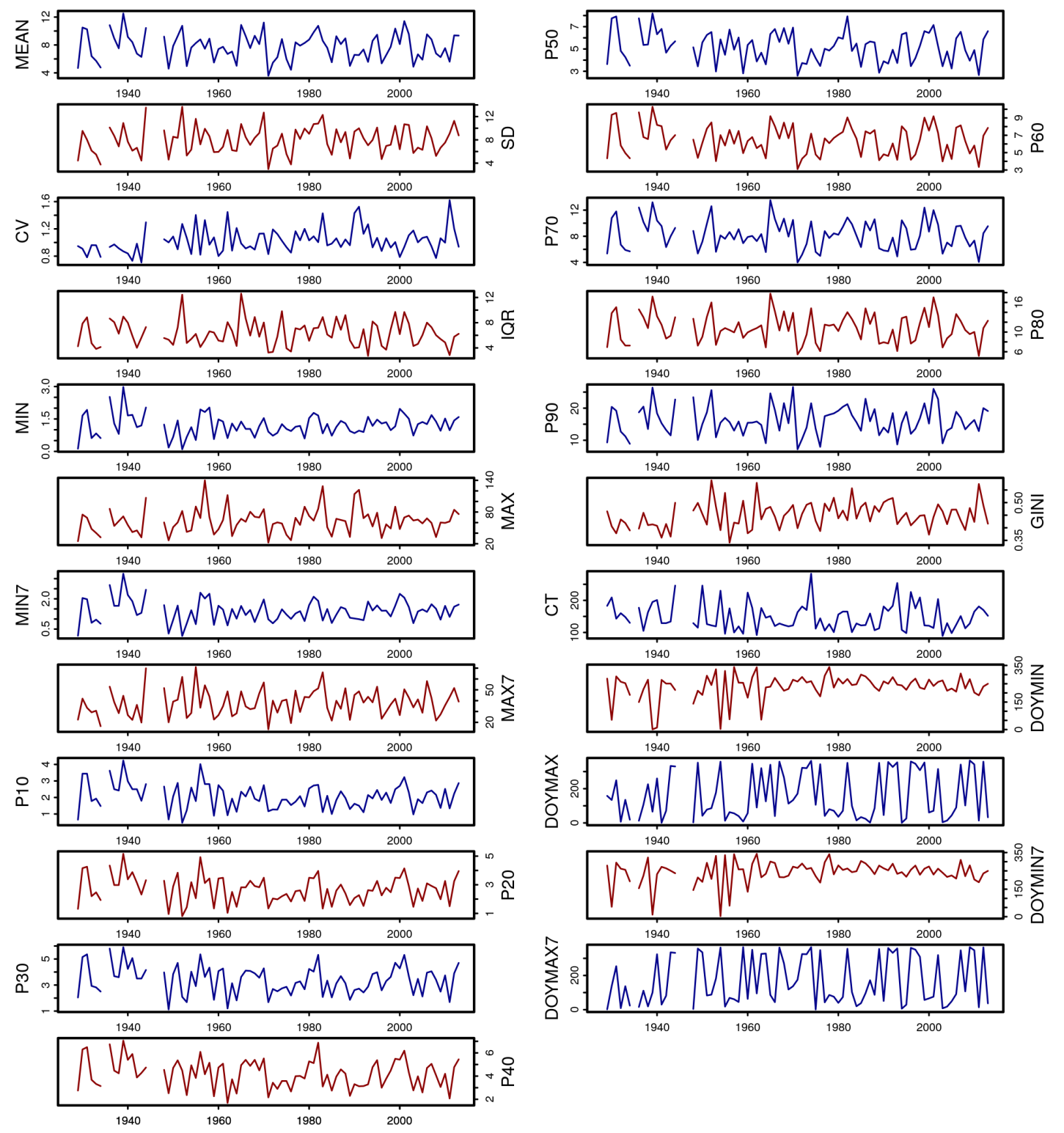

Figure 2. All considered indices at yearly resolution, shown for the River Wiese at Zell, south-western Germany. Yearly values are only displayed if they contain at least 350 reliable daily observations. See the text for details on units, interpretation and reliability classification.

\section{Homogeneity assessment}

\subsection{Methods for homogeneity assessment}

\subsubsection{Homogeneity tests}

Any environmental time series can be subject to inhomogeneities, i.e. unnatural sudden shifts in their statistical moments. In the simplest case, such inhomogeneities could be a jump in the mean between two time periods (see Fig. 5, top), but also changes in variability (e.g. reduced peak flows) or shifts in higher-order moments. The reasons for such inhomogeneities in streamflow time series are manifold, but they can "be related to changes in instrumentation, gauge restora- tion, recalibration of rating curves, flow regulation or channel engineering" (Gudmundsson and Seneviratne, 2016). As all the above-mentioned factors can be detrimental to a scientific investigation, it is essential to check time series against inhomogeneities. Here we apply a previously utilized collection of tests (Gudmundsson and Seneviratne, 2016), which is recommended by ECA\&D13 and has been thoroughly tested for temperature and precipitation indices (Wijngaard et al., 2003). This collection of tests contains (i) the standard normal homogeneity test (Alexandersson, 1986), (ii) the Buishand range test (Buishand, 1982), (iii) the Pettitt test (Pettitt, 1979), and (iv) the von Neumann ratio test (von Neumann, 1941). For the application of the above-mentioned collection 


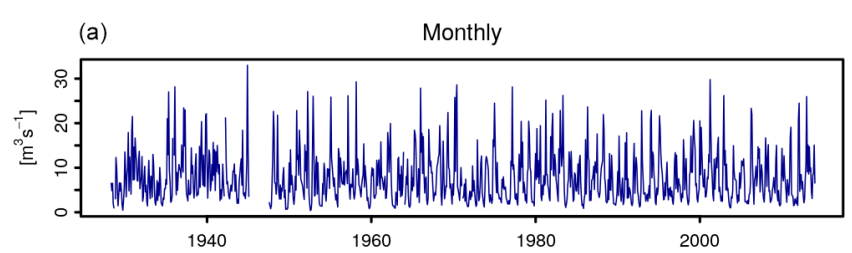

(b)

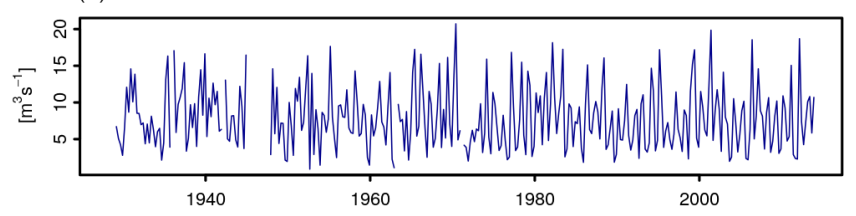

(c)

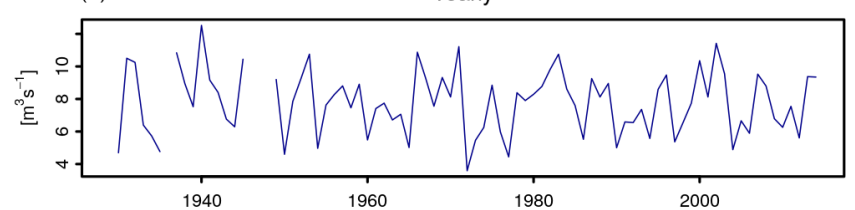

Figure 3. Monthly, seasonal, and yearly MEAN for the River Wiese at Zell, south-western Germany. Index values are only displayed if they fulfil the ECA\&D13 data availability criteria. See the text for details.

of tests, we rely on tables that provide critical values of the test statistics for a given sample size that have been determined using Monte Carlo methods (ECA\&D13). These tables only report critical values for a sample size of 20 and larger. Therefore, the tests can only be applied if at least 20 yearly, monthly or seasonal time steps are available. Prior to homogeneity testing, yearly, seasonal and monthly index values that are classified as unreliable according to ECA\&D13 (see Sect. 3.1.3) are set to missing. Missing values were removed after pre-whitening of yearly, seasonal and monthly index time series (see Sect. 4.1.2).

\subsubsection{Pre-whitening}

As the considered homogeneity tests rely at least on the assumption that the data are stationary, independent and identically distributed, all indices are pre-processed (prewhitened), aiming to reduce effects of (i) trends, (ii) seasonality, and (iii) serial correlation. For the pre-whitening procedure, linear trends and mean seasonal cycles were removed using a linear least-squares regression model which captures both the trend and the mean values as $x=b+a t$, where $b$ is the intercept, $a$ is the trend and $t$ is time.

1. For yearly indices, the linear model is fitted to and subtracted from the complete time series. This results in a time series with zero mean and no linear trend.

2. For seasonal indices, the linear model is fitted to and subtracted from the time series for each season (DJF, MAM, JJA, SON) individually. This results in a time series with seasonal resolution in which each season has a zero mean and no linear trend.

3. For monthly indices, the linear model is fitted to and extracted from the time series for each month (January, February, etc.) individually. This results in time series with monthly resolution in which each month has a zero mean and no linear trend.

As the detrended and de-seasonalized time series may still exhibit serial correlation, they were further pre-whitened by fitting a lag-1 autoregressive model and then obtaining the residuals, which are then subjected to the homogeneity analysis (Burn and Elnur, 2002; Chu et al., 2013; Gudmundsson and Seneviratne, 2016). The lag-1 autoregressive model is fitted using maximum likelihood estimation.

\subsubsection{Classification of station homogeneity}

To effectively combine the information of the four considered homogeneity tests, we classify the homogeneity of yearly, monthly and seasonal time-series indices following recommendations of ECA\&D13:

1. useful: one or no tests reject the null hypothesis at the $1 \%$ level;

2. doubtful: two tests reject the null hypothesis at the $1 \%$ level;

3. suspect: three or four tests reject the null hypothesis at the $1 \%$ level.

Note, however, that depending on the application, these rules may be either too relaxed or too conservative. In addition, we also introduce the following categories to account for special circumstances that can occur in this large-scale application:

4. not sufficient data: less than 20 yearly, seasonal or monthly reliable index values are available;

5. constant: all yearly, seasonal or monthly time steps have the same value;

6. error: an error (e.g. numerical convergence issue) occurred at any processing step.

\subsection{Homogeneity testing of all yearly, seasonal and monthly time-series indices}

The homogeneity analysis is applied to all indices at yearly, seasonal and monthly resolution. The rationale for applying the four tests to all indices individually is that inhomogeneities at a particular location might be relevant only for a subset of indices, while other indices are not affected. For example, it is possible that a change in instrumentation will affect peak flows, while low flows are not affected. For this homogeneity assessment, all yearly, seasonal and monthly 
(a)
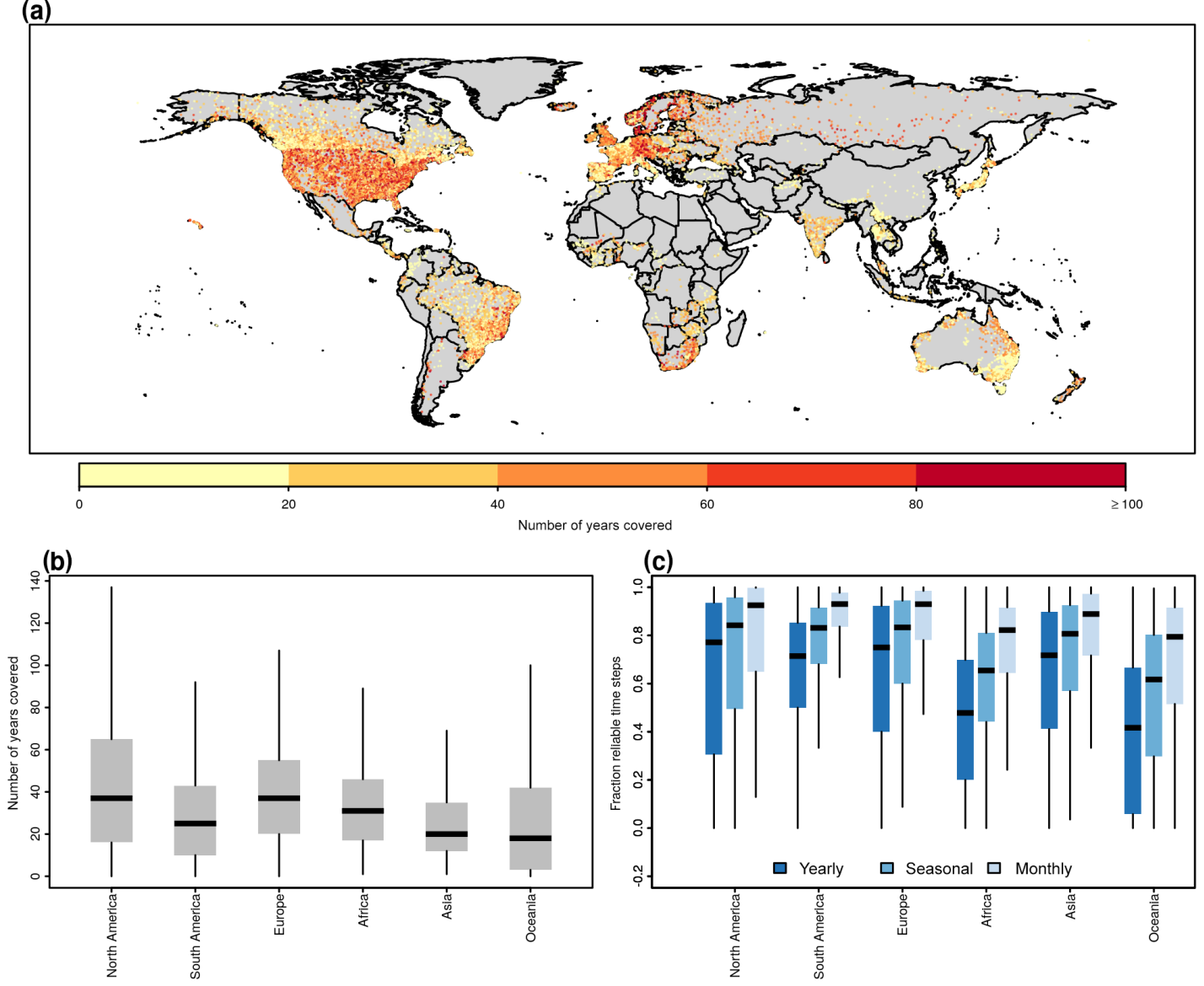

Figure 4. Temporal coverage of streamflow time-series indices. (a) Map of the number of years covered by each time series under consideration. (b) Distribution of the number of years available per time series for the continental regions of the world. (c) Distribution of the fraction of time steps that are classified as reliable using the ECA\&D13 data availability criteria. Boxplots show the interquartile range (box) and the median (vertical bar); the whiskers extend to the most extreme point, which is not more than 1.5 times the interquartile range away from the box; outliers are omitted.

time steps that are classified as reliable (Sect. 3.1.3) are considered. This results in a conservative assessment as (i) strict data-availability criteria are applied, and (ii) because inhomogeneities could occur in a time window not relevant to a study. Therefore, the presented results can be used for a general overview of time-series homogeneity, but their suitability should always be re-considered prior to specific applications.

Figure 5 illustrates the results of the homogeneity assessment for the MEAN index for the North Umpqua River in the US. The top panel shows the monthly MEAN index, which displays a sudden jump after the first third of the record. This jump may for example be the result of upstream flow regulation and would be detrimental for climatological investigations. The lower panel shows the time series after the above-mentioned pre-whitening procedure was applied. The seasonal cycle is effectively removed and obtaining the residuals from the lag- 1 autoregressive model reduced the magnitude of the sudden jump. Note also the spurious trend, which is an artefact of the de-trending that occurs in the presence of strong, sudden shifts in the mean. Nevertheless, three of the four considered tests identify this inhomogeneity at the 0.01 significance level, and the series is classified as suspect.

Global summaries of the number of stations in different homogeneity classes are shown in Fig. 6. Owing to the reduced number of time steps, the homogeneity testing could only be applied for approximately half of the locations at yearly resolution. Nevertheless, the homogeneity assessment highlights that the other half of the yearly indices can be considered "useful" at many locations. Only a small number of the low-flow indices (e.g. MIN, P10, P20, P30) had "constant" values and other issues were rarely detected. For both seasonal and monthly resolution, the number of stations with sufficient data for homogeneity assessment increased significantly, although it is important to recall that the homogeneity tests were in many cases applied to relatively short records (i.e. at least 20 seasons or 20 months respectively). Most of the seasonal and monthly time series with sufficient data are 
(a)
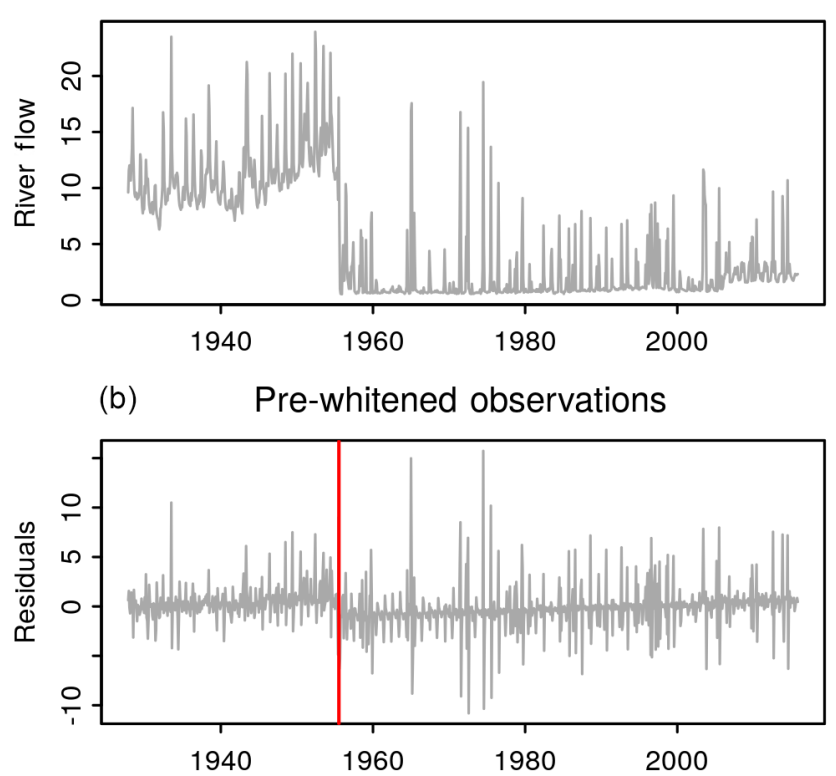

Figure 5. Homogeneity assessment of monthly mean flow of the North Umpqua River, US. (a) Monthly mean observations. (b) Prewhitened observations together with the time step at which the standard normal homogeneity test, the Buishand range test and the Pettitt test identified a breakpoint at the 0.01 significance level.

classified as "useful", but a number of "doubtful" and "suspect" values were also detected. At a few locations, low-flow indices had constant values.

Figure 7 shows continental summaries of the homogeneity assessment at yearly, seasonal and monthly timescales and highlights the number of stations at which all indices were classified as useful according to the ECA\&D13 criteria. Interestingly, the fraction of time series for which all indices have been classified as "useful" remains approximately constant irrespective of the considered time resolution. Figure 8 illustrates the effect of data availability criteria (Sect. 3.1.3) and the homogeneity assessment of the number of stations for each time step. Regardless of the temporal resolution, the number of stations reduces significantly when the homogeneity criterion is applied. This effect is more prominent at finer temporal resolution (monthly), as adding the "all indices homogenous" criterion removes approximately half of the eligible time series (bottom panel of Fig. 8). Note, however, that the presented summaries can only act as a rough guide on data availability, as criteria for including or excluding specific stations will depend on the objectives of individual future assessments.

\section{Data availability and overview of the data product}

\subsection{Data availability}

The data described in this paper are freely available as a compressed zip archive that can be downloaded from https:// doi.pangaea.de/10.1594/PANGAEA.887470 (Gudmundsson et al., 2018). The zip archive contains (i) a readme file, (ii) all time-series indices and (iii) the results of all homogeneity tests. Note that the data are accompanied by additional information on the data collection process, catchment boundaries and selected catchment properties (Do et al., 2018a, b).

\subsection{Time series of yearly, seasonal and annual indices}

The indices derived from daily streamflow time series as described in Sects. 2 and 3 are stored in the INDICES directory. To address the different temporal resolution of the available indices (yearly, seasonal and monthly scales), the GSIM indices were organized into three respective subdirectories where each GSIM station is represented through a text file. For instance, indices at yearly resolution derived from the station with the identifier "AR_0000006" are stored as a text file called "AR_0000006.year" in the "yearly" sub-directory. Indices at seasonal and monthly resolution are stored as "AR_0000006.seas" and "AR_0000006.mon" in the respective ("seasonal", "monthly") sub-directories.

An identical data structure was adopted across all timeseries files, with basic metadata (e.g. station identifier, station name, river name) stored in the header, and all index time series written in subsequent lines as a table, where (i) the first column contains the date, which is by convention the last day of the respective yearly, seasonal or monthly time step; (ii) the subsequent columns contain the index values, with column names corresponding to the abbreviations introduced in Table 4; and (iii) the last two columns contain information on the number of (missing) daily values used to compute the index.

\subsection{Homogeneity of time-series indices}

The results of the homogeneity analysis are stored in three tables, representing indices at yearly, seasonal and monthly resolution which are placed in the HOMOGENEITY directory and contain information on all stations. There is an identical structure for these three text files, with the first 13 columns containing important metadata such as the station identifier, name of the gauging location, and first and last time steps of the index time series. The remaining columns contain the results of four homogeneity tests that are described in the paper, and thus each index is accompanied by four columns (corresponding to the results of the (1) standard normal homogeneity test, (2) the Buishand range test, (3) the Pettitt test and (4) the Neuman ratio test). 

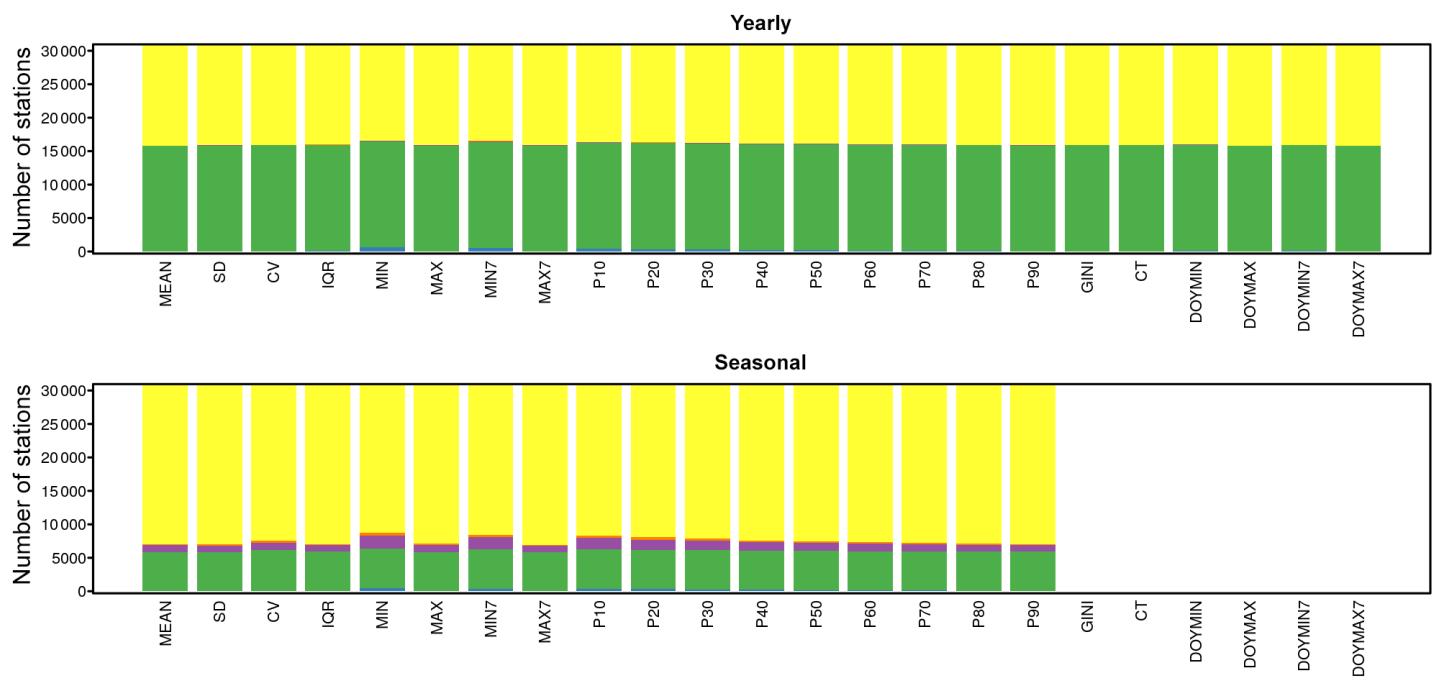

Monthly

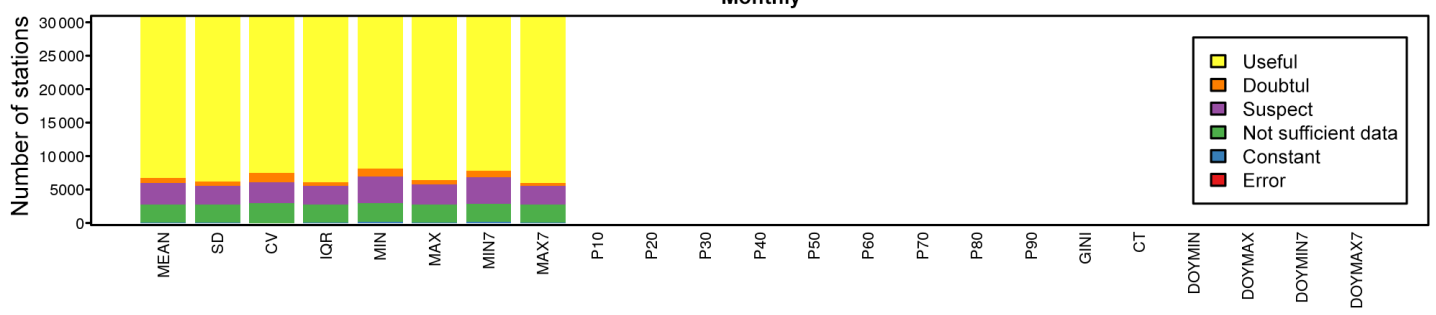

Figure 6. Global summary of the homogeneity analysis for all considered indices at yearly, seasonal and monthly resolution. Shown are the number of stations that are classified as (1) useful, (2) doubtful, (3) suspect, (4) not sufficient data, (5) constant and (6) error according to Sect. 4.1.3. Note that all six categories do occur, although some of them are rare and thus barely visible in the figure.
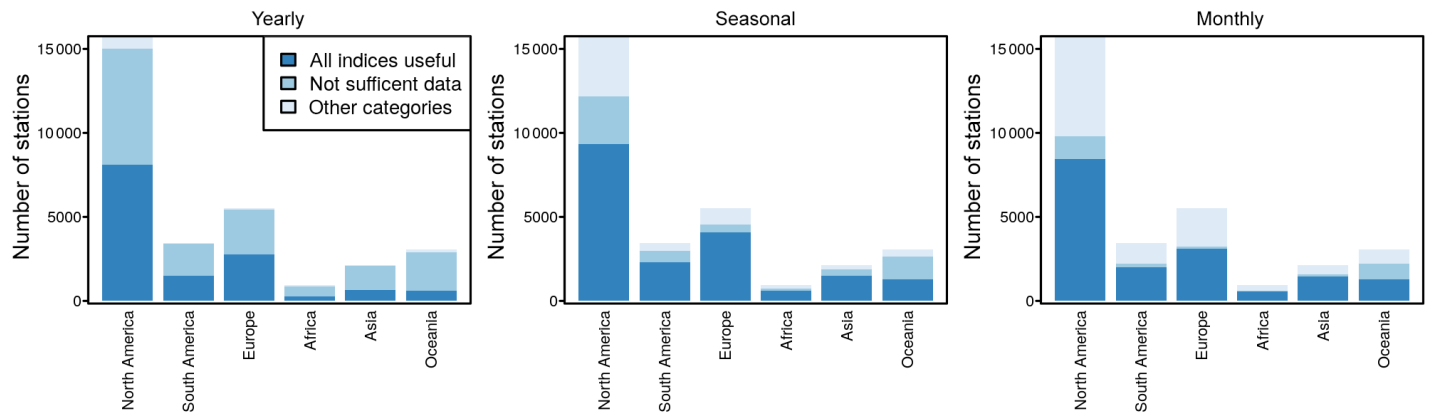

Figure 7. Continental summary of the homogeneity analysis for yearly, seasonal and monthly indices. Shown are the total number of stations at which all indices are classified as useful according to the criteria of ECA\&D13, stations that did not have sufficient data for the application of the homogeneity analysis, and all other stations (other categories).

\section{Summary and conclusions}

Together with Do et al. (2018a) (Part 1), this paper presents the Global Streamflow Indices and Metadata Archive (GSIM), which is a unique collection of streamflow observations at more than 30000 stations around the globe. In Part 1 (Do et al., 2018a) of the paper series we focussed on the collection and merging of freely available streamflow data worldwide. Part 1 also introduced shapefiles of catchment boundaries together with essential catchment properties such as land cover, topography and mean climatic conditions. As not all data providers allow for a free distribution of unprocessed daily values, we followed in Part 2 an approach that has been established through the ETCCDI in climate research (Klein Tank et al., 2009; Zhang et al., 2011) and introduced a set of time-series indices that can be used to assess the water balance, seasonality, low flows and floods, which are made freely available to serve the scientific community.

While focussing on time-series indices facilitates the redistribution of the data, this approach inevitably comes with 

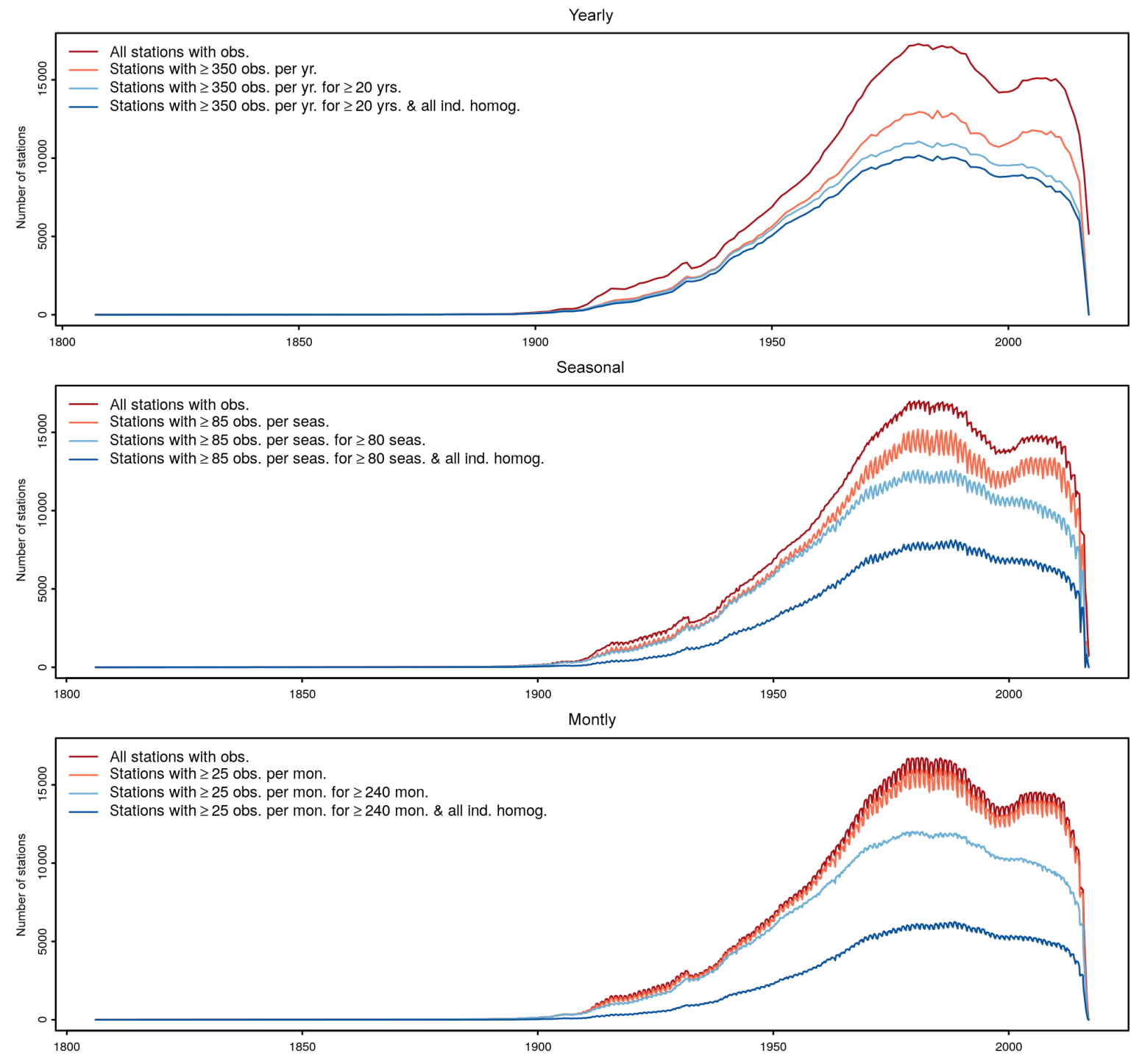

Figure 8. Temporal evolution of global station coverage, conditional on different data-selection criteria for yearly, monthly and seasonal timescales. Successively, the following criteria are applied: (i) all stations that at least one observation for the respective time step (i.e. year, season, month). (ii) Stations that have at least a critical number of observations for each time step (critical values depend on the timescale; see Sect. 3.1.3). (iii) Stations that have at least a critical number of observations for the equivalent of 20 station years (i.e. 20 yearly values, $20 \times 4=80$ seasonal values, $20 \times 12=240$ monthly values). (iv) Stations where criterion (iii) applied and all indices were considered to be useful in the homogeneity analysis (see Sect. 4.1.3).

inherent limitations. For example, many applications, including hydrological or ecological modelling, may require daily resolution data and other studies may depend on indices not included in the presented collections. Consequently, some users may prefer to seek out the original data sources (see details in Do et al., 2018a) and access the raw daily streamflow values in that manner. Nevertheless, we would like to also highlight the advantages of time-series indices: a benefit of having pre-processed the daily streamflow data into indices is that they can be readily used in studies across large regions with minimal handling of raw data files. In addition, the selected indices foster a wide variety of assessments, including water balance calculations, extreme event analysis and the identifications of trends in the world's freshwater resources.

To ensure the reliability of the published data, we first evaluated the quality of individual daily values through a combination of quality flags developed by the data providers and a transparent numerical screening approach. Subsequently, the homogeneity of yearly, seasonal and monthly indices was assessed using reproducible methods, aiming at aiding potential users to gauge the suitability of individual time series for their research questions. Note, however, that it is not the intent of this project to derive a single "best" dataset, for example, by considering a pre-defined baseline period which 
gauges must cover, or by derivation of a so-called "highquality" dataset by applying a rigorous set of quality criteria to available stations. While these approaches are of high value if a dataset is tailored to a specific application, the emphasis of GSIM is to provide a large database of streamflow observations by collating and standardizing many data sources around the world.

Given that data quality requirements can vary substantially, it will remain the work of individual users to establish selection criteria for each study, thereby finding a trade-off between data quantity (number of gauges) and data quality (record length, missing periods). While the criteria used to gauge the usability of the indices are based on the recommendations of ECA\&D13, they necessarily rely on subjective decisions on what constitutes a "reliable index". For example, in some climates a gauge may be "reliable" and yet unable to provide measurements for part of the year (e.g. seasonally dry or cold climates). For this reason, attempts have been made to provide flexibility, aiming at facilitating the user to judge upon "reliability" in the context of their applications. Nonetheless, it is our hope that enabling a wide usage of streamflow indices might also lead to greater scrutiny of the data, accumulated knowledge of performance of each site and improved methods for judging the quality of streamflow observations.

There are numerous unsettled scientific questions at the global scale that this dataset has the potential to support. For example, there are unresolved questions around the relationship between trends in rainfall extremes and hydrological extremes (Do et al., 2017; Westra et al., 2013), as well as developing a better understanding of the influence of human activities on the hydrological cycle more broadly (Barnett et al., 2008; Blöschl et al., 2017; Destouni et al., 2013; Gudmundsson et al., 2017; Hegerl et al., 2015; Jaramillo and Destouni, 2015). Expanding upon recent methodological developments (Gudmundsson and Seneviratne, 2015, 2016), the newly assembled data may act as a basis for developing gridded global-scale observation-based data products. There are also likely to be many applications in fields as diverse as hydro-ecology, water quality modelling, environmental assessment and socio-hydrology. We therefore expect the presented data to be a valuable source of information to answer pending questions in global freshwater research, e.g. in the context of the World Climate Research Program Grand Challenge on Water Availability (Trenberth and Asrar, 2014) or the international research efforts on "Change in hydrology and society" (Montanari et al., 2013).

The significant increase in global gauge density and record length through the GSIM archive would not have been possible without the fact that water agencies are increasingly making data accessible online. However, the benefits of this new collection are overshadowed by challenges that are essentially bureaucratic in nature: how to systematically collate, maintain and improve streamflow data globally and who should do it. While agencies such as the GRDC would pro- vide a natural fit for this type of task, they are currently constrained in their capacity to commit to a regular and systematic upkeep of such a global dataset. This paper series represents a one-off initiative of the authors, requiring over a year's worth of checking and evaluation and with little to no capacity for updating or extending the dataset. While it is possible that updates might be achieved through similar future efforts from the community, they are likely to be ad hoc and far from ideal. There are many troubles that can result from patchwork efforts of data collating, including (i) orphaned versions that persist in usage despite updated data being available, (ii) gauges or regions becoming outof-sync, (iii) repeated needs to identify duplicates in overlapping datasets, (iv) information loss between versions and poor upkeep of documentation, (v) competing or "forked" databases, and many more. To remedy this situation, the hydrological community needs to collectively improve the organization of initiatives for coordinated systems that facilitate updating, storage and documentation of existing data, and to lobby for existing closed databases to be made open and accessible. As part of a global imperative for improved streamflow data, there are a number of additional activities researchers might undertake. These include (i) providing new analyses that improve the quality and understanding of the existing database; (ii) developing new automated methods that can be used systematically to maintain or improve the quality of the instrumental record; (iii) providing additional streamflow observations from missing or currently inaccessible datasets; and (iv) deriving new observational data products though better ground-truthing of remote-sensed variables, reanalysis from hydrological models or upscaling of in situ observations using machine learning.

Competing interests. The authors declare that they have no conflict of interest.

Acknowledgements. We would like to thank Sonia I. Seneviratne for the fruitful discussions on the creation of the GSIM archive. This work would not have been possible without the tremendous efforts of regional, national and international organizations in collecting and archiving river flow observations. Their work is highly appreciated.

Edited by: David Carlson

Reviewed by: Wolfgang Grabs and one anonymous referee

\section{References}

Alexander, L. V., Zhang, X., Peterson, T. C., Caesar, J., Gleason, B., Klein Tank, A. M. G., Haylock, M., Collins, D., Trewin, B., Rahimzadeh, F., Tagipour, A., Rupa Kumar, K., Revadekar, J., Griffiths, G., Vincent, L., Stephenson, D. B., Burn, J., Aguilar, E., Brunet, M., Taylor, M., New, M., Zhai, P., Rusticucci, M., and 
Vazquez-Aguirre, J. L.: Global observed changes in daily climate extremes of temperature and precipitation, J. Geophys. Res., 111, D05109, https://doi.org/10.1029/2005JD006290, 2006.

Alexandersson, H.: A homogeneity test applied to precipitation data, J. Climatol., 6, 661-675, 1986.

Alkama, R., Marchand, L., Ribes, A., and Decharme, B.: Detection of global runoff changes: results from observations and CMIP5 experiments, Hydrol. Earth Syst. Sci., 17, 2967-2979, https://doi.org/10.5194/hess-17-2967-2013, 2013.

Barnett, T. P., Pierce, D. W., Hidalgo, H. G., Bonfils, C., Santer, B. D., Das, T., Bala, G., Wood, A. W., Nozawa, T., Mirin, A. A., Cayan, D. R., and Dettinger, M. D.: Human-Induced Changes in the Hydrology of the Western United States, Science, 319, 10801083, 2008.

Beck, H. E., de Roo, A., and van Dijk, A. I. J. M.: Global maps of streamflow characteristics based on observations from several thousand catchments, J. Hydrometeorol., 16, 1478-1501, 2015.

Beck, H. E., van Dijk, A. I. J. M., de Roo, A., Dutra, E., Fink, G., Orth, R., and Schellekens, J.: Global evaluation of runoff from 10 state-of-the-art hydrological models, Hydrol. Earth Syst. Sci., 21, 2881-2903, https://doi.org/10.5194/hess-21-2881-2017, 2017.

Becker, A., Finger, P., Meyer-Christoffer, A., Rudolf, B., Schamm, K., Schneider, U., and Ziese, M.: A description of the global land-surface precipitation data products of the Global Precipitation Climatology Centre with sample applications including centennial (trend) analysis from 1901-present, Earth Syst. Sci. Data, 5, 71-99, https://doi.org/10.5194/essd-5-71-2013, 2013.

Blöschl, G., Hall, J., Parajka, J., Perdigão, R. A. P., Merz, B., Arheimer, B., Aronica, G. T., Bilibashi, A., Bonacci, O., Borga, M., v Canjevac, I., Castellarin, A., Chirico, G. B., Claps, P., Fiala, K., Frolova, N., Gorbachova, L., Gül, A., Hannaford, J., Harrigan, S., Kireeva, M., Kiss, A., Kjeldsen, T. R., Kohnová, S., Koskela, J. J., Ledvinka, O., Macdonald, N., MavrovaGuirguinova, M., Mediero, L., Merz, R., Molnar, P., Montanari, A., Murphy, C., Osuch, M., Ovcharuk, V., Radevski, I., Rogger, M., Salinas, J. L., Sauquet, E., Sraj, M., Szolgay, J., Viglione, A., Volpi, E., Wilson, D., Zaimi, K., and Zivković, N.: Changing climate shifts timing of European floods, Science, 357, 588-590, 2017.

Buishand, T. A.: Some methods for testing the homogeneity of rainfall records, J. Hydrol., 58, 11-27, 1982.

Burn, D. H. and Elnur, M. A. H.: Detection of hydrologic trends and variability, J. Hydrol., 255, 107-122, 2002.

Ceriani, L. and Verme, P.: The origins of the Gini index: extracts from Variabilità e Mutabilità (1912) by Corrado Gini, J. Econ. Inequal., 10, 421-443, 2012.

Chu, M. L., Ghulam, A., Knouft, J. H., and Pan, Z.: A Hydrologic Data Screening Procedure for Exploring Monotonic Trends and Shifts in Rainfall and Runoff Patterns, J. Am. Water Resour. As., 50, 928-942, https://doi.org/10.1111/jawr.12149, 2013.

Cunderlik, J. M. and Ouarda, T. B. M. J.: Trends in the timing and magnitude of floods in Canada, J. Hydrol., 375, 471-480, 2009.

Dee, D. P., Uppala, S. M., Simmons, A. J., Berrisford, P., Poli, P., Kobayashi, S., Andrae, U., Balmaseda, M. A., Balsamo, G., Bauer, P., Bechtold, P., Beljaars, A. C. M., van de Berg, L., Bidlot, J., Bormann, N., Delsol, C., Dragani, R., Fuentes, M., Geer, A. J., Haimberger, L., Healy, S. B., Hersbach, H., Hólm, E. V., Isaksen, L., Kållberg, P., Köhler, M., Matricardi, M., McNally, A. P., Monge-Sanz, B. M., Morcrette, J. J., Park, B. K., Peubey,
C., de Rosnay, P., Tavolato, C., Thépaut, J. N., and Vitart, F.: The ERA-Interim reanalysis: configuration and performance of the data assimilation system, Q. J. Roy. Meteor. Soc., 137, 553-597, 2011.

Destouni, G., Jaramillo, F., and Prieto, C.: Hydroclimatic shifts driven by human water use for food and energy production, Nat. Clim. Change, 3, 213-217, 2013.

Do, H. X., Westra, S., and Leonard, M.: A global-scale investigation of trends in annual maximum streamflow, J. Hydrol., 552, 28-43, 2017.

Do, H. X., Gudmundsson, L., Leonard, M., and Westra, S.: The Global Streamflow Indices and Metadata Archive (GSIM) - Part 1: The production of a daily streamflow archive and metadata, Earth Syst. Sci. Data, 10, 765-785, https://doi.org/10.5194/essd10-765-2018, 2018a.

Do, H. X., Gudmundsson, L., Leonard, M., and Westra, S.: The Global Streamflow Indices and Metadata Archive Part 1: Station catalog and Catchment boundary, PANGAEA, https://doi.pangaea.de/10.1594/PANGAEA.887477, 2018b.

ECA \& D Project Team and Royal Netherlands Meteorological Institute: Algorithm Theoretical Basis Document (ATBD), available at: https://www.ecad.eu/documents/atbd.pdf, 2013.

Ehsanzadeh, E. and Adamowski, K.: Trends in timing of low stream flows in Canada: impact of autocorrelation and long-term persistence, Hydrol. Process., 24, 970-980, 2010.

Fekete, B. M., Looser, U., Pietroniro, A., and Robarts, R. D.: Rationale for Monitoring Discharge on the Ground, J. Hydrometeorol., 13, 1977-1986, 2012.

Fekete, B. M., Robarts, R. D., Kumagai, M., Nachtnebel, H.-P., Odada, E., and Zhulidov, A. V.: Time for in situ renaissance, Science, 349, 685-686, 2015.

Frich, P., Alexander, L. V., Della-Marta, P., Gleason, B., Haylock, M., Tank, A. M. G. K., and Peterson, T.: Observed coherent changes in climatic extremes during the second half of the twentieth century, Clim. Res., 19, 193-212, 2002.

Gudmundsson, L. and Seneviratne, S. I.: Towards observationbased gridded runoff estimates for Europe, Hydrol. Earth Syst. Sci., 19, 2859-2879, https://doi.org/10.5194/hess-19-2859-2015, 2015.

Gudmundsson, L. and Seneviratne, S. I.: Observation-based gridded runoff estimates for Europe (E-RUN version 1.1), Earth Syst. Sci. Data, 8, 279-295, https://doi.org/10.5194/essd-8-279-2016, 2016.

Gudmundsson, L., Tallaksen, L. M., and Stahl, K.: Spatial crosscorrelation patterns of European low, mean and high flows, Hydrol. Process., 25, 1034-1045, 2011.

Gudmundsson, L., Tallaksen, L. M., Stahl, K., Clark, D. B., Dumont, E., Hagemann, S., Bertrand, N., Gerten, D., Heinke, J., Hanasaki, N., Voss, F., and Koirala, S.: Comparing Large-Scale Hydrological Model Simulations to Observed Runoff Percentiles in Europe, J. Hydrometeorol., 13, 604-620, 2012a.

Gudmundsson, L., Wagener, T., Tallaksen, L. M., and Engeland, K.: Evaluation of nine large-scale hydrological models with respect to the seasonal runoff climatology in Europe, Water Resour. Res., 48, W11504, https://doi.org/10.1111/jawr.12149, 2012b.

Gudmundsson, L., Seneviratne, S. I., and Zhang, X.: Anthropogenic climate change detected in European renewable freshwater resources, Nat. Clim. Change, 7, 813-816, 2017. 
Gudmundsson, L., Do, H. X., Leonard, M., and Westra, S.: The Global Streamflow Indices and Metadata Archive (GSIM) - Part 2: Time Series Indices and Homogeneity Assessment, PANGAEA, https://doi.pangaea.de/10.1594/PANGAEA.887470, 2018.

Haddeland, I., Clark, D. B., Franssen, W., Ludwig, F., Voß, F., Arnell, N. W., Bertrand, N., Best, M., Folwell, S., Gerten, D., Gomes, S., Gosling, S. N., Hagemann, S., Hanasaki, N., Harding, R., Heinke, J., Kabat, P., Koirala, S., Oki, T., Polcher, J., Stacke, T., Viterbo, P., Weedon, G. P., and Yeh, P.: Multimodel Estimate of the Global Terrestrial Water Balance: Setup and First Results, J. Hydrometeorol., 12, 869-884, 2011.

Hall, J., Arheimer, B., Aronica, G. T., Bilibashi, A., Boháč, M., Bonacci, O., Borga, M., Burlando, P., Castellarin, A., Chirico, G. B., Claps, P., Fiala, K., Gaál, L., Gorbachova, L., Gül, A., Hannaford, J., Kiss, A., Kjeldsen, T., Kohnová, S., Koskela, J. J., Macdonald, N., Mavrova-Guirguinova, M., Ledvinka, O., Mediero, L., Merz, B., Merz, R., Molnar, P., Montanari, A., Osuch, M., Parajka, J., Perdigão, R. A. P., Radevski, I., Renard, B., Rogger, M., Salinas, J. L., Sauquet, E., Šraj, M., Szolgay, J., Viglione, A., Volpi, E., Wilson, D., Zaimi, K., and Blöschl, G.: A European Flood Database: facilitating comprehensive flood research beyond administrative boundaries, P. Int. Ass. Hydrol. Sci., 370, 89-95, 2015.

Hannah, D. M., Demuth, S., van Lanen, H. A. J., Looser, U., Prudhomme, C., Rees, G., Stahl, K., and Tallaksen, L. M.: Large-scale river flow archives: importance, current status and future needs, Hydrol. Process., 25, 1191-1200, 2011.

Harris, I., Jones, P. D., Osborn, T. J., and Lister, D. H.: Updated high-resolution grids of monthly climatic observations - the CRU TS3.10 Dataset, Int. J. Climatol., 34, 623-642, 2014.

Haylock, M. R., Hofstra, N., Klein Tank, A. M. G., Klok, E. J., Jones, P. D., and New, M.: A European daily highresolution gridded data set of surface temperature and precipitation for 1950-2006, J. Geophys. Res., 113, D20119, https://doi.org/10.1029/2008JD010201, 2008.

Hegerl, G. C., Black, E., Allan, R. P., Ingram, W. J., Polson, D., Trenberth, K. E., Chadwick, R. S., Arkin, P. A., Sarojini, B. B., Becker, A., Dai, A., Durack, P. J., Easterling, D., Fowler, H. J., Kendon, E. J., Huffman, G. J., Liu, C., Marsh, R., New, M., Osborn, T. J., Skliris, N., Stott, P. A., Vidale, P.-L., Wijffels, S. E., Wilcox, L. J., Willett, K. M., and Zhang, X.: Challenges in quantifying changes in the global water cycle, B. Am. Meteorol. Soc., 96, 1097-1115, 2015.

Hidalgo, H. G., Das, T., Dettinger, M. D., Cayan, D. R., Pierce, D. W., Barnett, T. P., Bala, G., Mirin, A., Wood, A. W., Bonfils, C., Santer, B. D., and Nozawa, T.: Detection and Attribution of Streamflow Timing Changes to Climate Change in the Western United States, J. Climate, 22, 3838-3855, 2009.

Hisdal, H., Stahl, K., Tallaksen, L. M., and Demuth, S.: Have streamflow droughts in Europe become more severe or frequent?, Int. J. Climatol., 21, 317-333, 2001.

Hodgkins, G. A., Whitfield, P. H., Burn, D. H., Hannaford, J., Renard, B., Stahl, K., Fleig, A. K., Madsen, H., Mediero, L., Korhonen, J., Murphy, C., and Wilson, D.: Climate-driven variability in the occurrence of major floods across North America and Europe, J. Hydrol., 552, 704-717, 2017.
Jaramillo, F. and Destouni, G.: Local flow regulation and irrigation raise global human water consumption and footprint, Science, 350, 1248-1251, 2015.

Katz, R. W., Parlange, M. B., and Naveau, P.: Statistics of extremes in hydrology, Adv. Water Resour., 25, 1287-1304, 2002.

Klein Tank, A. M. G., Zwiers, F. W., and Zhang, X.: Guidelines on Analysis of extremes in a changing climate in support of informed decisions for adaptation, available at: https://www.ecad. eu/documents/WCDMP_72_TD_1500_en_1.pdf, 2009.

Kumar, S., Merwade, V., Kam, J., and Thurner, K.: Streamflow trends in Indiana: Effects of long term persistence, precipitation and subsurface drains, J. Hydrol., 374, 171-183, 2009.

Kundzewicz, Z. W., Graczyk, D., Maurer, T., Piskwar, I., Radziejewski, M., Svensson, C., and Szwed, M. G.: Trend detection in river flow series: 1 . Annual maximum flow, Hydrolog. Sci. J., 50, 797-810, 2005.

Lettenmaier, D. P., Wood, E. F., and Wallis, J. R.: HydroClimatological Trends in the Continental United States, 194888, J. Climate, 7, 586-607, 1994.

Lins, H. F. and Slack, J. R.: Streamflow trends in the United States, Geophys. Res. Lett., 26, 227-230, 1999.

Loon, V. and Anne, F.: Hydrological drought explained, Wiley Interdisciplinary Reviews: Water, 2, 359-392, 2015.

Masaki, Y., Hanasaki, N., Takahashi, K., and Hijioka, Y.: Globalscale analysis on future changes in flow regimes using Gini and Lorenz asymmetry coefficients, Water Resour. Res., 50, 40544078, 2014.

McCabe, G. J. and Wolock, D. M.: A step increase in streamflow in the conterminous United States, Geophys. Res. Lett., 29, 21852185, 2002.

McKee, T. B., Doesken, N. J., and Kleist, J.: The relationship of drought frequency and duration to time scales, 8th Conference on Applied Climatology, 179-184, 1993.

Milly, P. C. D., Dunne, K. A., and Vecchia, A. V.: Global pattern of trends in streamflow and water availability in a changing climate, Nature, 438, 347-350, 2005.

Montanari, A., Young, G., Savenije, H. H. G., Hughes, D., Wagener, T., Ren, L. L., Koutsoyiannis, D., Cudennec, C., Toth, E., Grimaldi, S., Blöschl, G., Sivapalan, M., Beven, K., Gupta, H., Hipsey, M., Schaefli, B., Arheimer, B., Boegh, E., Schymanski, S. J., Di Baldassarre, G., Yu, B., Hubert, P., Huang, Y., Schumann, A., Post, D. A., Srinivasan, V., Harman, C., Thompson, S., Rogger, M., Viglione, A., McMillan, H., Characklis, G., Pang, Z., and Belyaev, V.: "Panta Rhei-Everything Flows": Change in hydrology and society - The IAHS Scientific Decade 2013-2022, Hydrolog. Sci. J., 58, 1256-1275, 2013.

Moore, J. N., Harper, J. T., and Greenwood, M. C.: Significance of trends toward earlier snowmelt runoff, Columbia and Missouri Basin headwaters, western United States, Geophys. Res. Lett., 34, L16402, https://doi.org/10.1029/2007GL031022, 2007.

Oki, T. and Kanae, S.: Global Hydrological Cycles and World Water Resources, Science, 313, 1068-1072, 2006.

Olden, J. D. and Poff, N. L.: Redundancy and the choice of hydrologic indices for characterizing streamflow regimes, River Res. Appl., 19, 101-121, 2003.

Oliveira, P. J. C., Davin, E. L., Levis, S., and Seneviratne, S. I.: Vegetation-mediated impacts of trends in global radiation on land hydrology: a global sensitivity study, Glob. Change Biol., 17, 3453-3467, 2011. 
Pettitt, A. N.: A Non-Parametric Approach to the Change-Point Problem, J. Roy. Stat. Soc. C-App., 28, 126-135, 1979.

Poli, P., Hersbach, H., Dee, D. P., Berrisford, P., Simmons, A. J., Vitart, F., Laloyaux, P., Tan, D. G. H., Peubey, C., Thépaut, J.N., Trémolet, Y., Hólm, E. V., Bonavita, M., Isaksen, L., and Fisher, M.: ERA-20C: An Atmospheric Reanalysis of the Twentieth Century, J. Climate, 29, 4083-4097, 2016.

Rajah, K., OĹeary, T., Turner, A., Petrakis, G., Leonard, M., and Westra, S.: Changes to the temporal distribution of daily precipitation, Geophys. Res. Lett., 41, 8887-8894, 2014.

Rauscher, S. A., Pal, J. S., Diffenbaugh, N. S., and Benedetti, M. M.: Future changes in snowmelt-driven runoff timing over the western US, Geophys. Res. Lett., 35, L16703, https://doi.org/10.1029/2008GL034424, 2008.

Reek, T., Doty, S. R., and Owen, T. W.: A Deterministic Approach to the Validation of Historical Daily Temperature and Precipitation Data from the Cooperative Network, B. Am. Meteorol. Soc., 73, 753-762, 1992.

Regonda, S. K., Rajagopalan, B., Clark, M., and Pitlick, J.: Seasonal Cycle Shifts in Hydroclimatology over the Western United States, J. Climate, 18, 372-384, 2005.

Sawicz, K., Wagener, T., Sivapalan, M., Troch, P. A., and Carrillo, G.: Catchment classification: empirical analysis of hydrologic similarity based on catchment function in the eastern USA, Hydrol. Earth Syst. Sci., 15, 2895-2911, https://doi.org/10.5194/hess-15-2895-2011, 2011.

Sawicz, K. A., Kelleher, C., Wagener, T., Troch, P., Sivapalan, M., and Carrillo, G.: Characterizing hydrologic change through catchment classification, Hydrol. Earth Syst. Sci., 18, 273-285, https://doi.org/10.5194/hess-18-273-2014, 2014.

Shiklomanov, I. A., Babkin, V. I., Penkova, N. V., Georgievsry, V. Y., Zaretskaya, I. P., Izmailova, A. V., Balonishnikova, J. A., Grigorkina, T. E., Grube, T. V., Skoryatina, K. V., Tsytsenko, and Yunitsyna, V. P.: World Water Resources at the Beginning of the Twenty-First Century, Cambridge University Press, 2004.

Shukla, S. and Wood, A. W.: Use of a standardized runoff index for characterizing hydrologic drought, Geophys. Res. Lett., 35, L02405, https://doi.org/10.1029/2007GL032487, 2008.

Sippel, S., Zscheischler, J., Heimann, M., Otto, F. E. L., Peters, J., and Mahecha, M. D.: Quantifying changes in climate variability and extremes: Pitfalls and their overcoming, Geophys. Res. Lety., 42, 9990-9998, 2015.

Small, D., Islam, S., and Vogel, R. M.: Trends in precipitation and streamflow in the eastern US: Paradox or perception?, Geophys. Res. Lett., 33, L03403, https://doi.org/10.1029/2005GL024995, 2006.

Stahl, K., Hisdal, H., Hannaford, J., Tallaksen, L. M., van Lanen, H. A. J., Sauquet, E., Demuth, S., Fendekova, M., and Jódar, J.: Streamflow trends in Europe: evidence from a dataset of nearnatural catchments, Hydrol. Earth Syst. Sci., 14, 2367-2382, https://doi.org/10.5194/hess-14-2367-2010, 2010.
Stahl, K., Tallaksen, L. M., Hannaford, J., and van Lanen, H. A. J.: Filling the white space on maps of European runoff trends: estimates from a multi-model ensemble, Hydrol. Earth Syst. Sci., 16, 2035-2047, https://doi.org/10.5194/hess-16-2035-2012, 2012.

Stewart, I. T., Cayan, D. R., and Dettinger, M. D.: Changes toward Earlier Streamflow Timing across Western North America, J. Climate, 18, 1136-1155, 2005.

Svensson, C., Kundzewicz, W. Z., and Maurer, T.: Trend detection in river flow series: 2 . Flood and low-flow index series, Hydrolog. Sci. J., 50, 811-824, 2005.

Tallaksen, L. M. and van Lanen, H. A. J.: Hydrological Drought: Processes and Estimation Methods for Streamflow and Groundwater, Elsevier, 2004.

Tallaksen, L. M., Madsen, H., and Clausen, B.: On the definition and modelling of streamflow drought duration and deficit volume, Hydrolog. Sci. J., 42, 15-33, 1997.

Trenberth, K. E. and Asrar, G. R.: Challenges and Opportunities in Water Cycle Research: WCRP Contributions, Surv. Geophys., 35, 515-532, 2014.

Vogel, R. M. and Fennessey, N. M.: Flow-Duration Curves. I: New Interpretation and Confidence Intervals, J. Water Res. Plan. Man., 120, 485-504, 1994.

von Neumann, J.: Distribution of the Ratio of the Mean Square Successive Difference to the Variance, Ann. Math. Stat., 12, 367395, 1941.

Vörösmarty, C. J., Green, P., Salisbury, J., and Lammers, R. B.: Global Water Resources: Vulnerability from Climate Change and Population Growth, Science, 289, 284-288, 2000.

Westerberg, I. K., Wagener, T., Coxon, G., McMillan, H. K., Castellarin, A., Montanari, A., and Freer, J.: Uncertainty in hydrological signatures for gauged and ungauged catchments, Water Resour. Res., 52, 1847-1865, 2016.

Westra, S., Alexander, L. V., and Zwiers, F. W.: Global Increasing Trends in Annual Maximum Daily Precipitation, J. Climate, 26, 3904-3918, 2013.

Wijngaard, J. B., Klein Tank, A. M. G., and Können, G. P.: Homogeneity of 20th century European daily temperature and precipitation series, Int. J. Climatol., 23, 679-692, 2003.

Zaitchik, B. F., Rodell, M., and Olivera, F.: Evaluation of the Global Land Data Assimilation System using global river discharge data and a source-to-sink routing scheme, Water Resour. Res., 46, W06507, https://doi.org/10.1029/2009WR007811, 2010.

Zhang, X., Harvey, K. D., Hogg, W. D., and Yuzyk, T. R.: Trends in Canadian streamflow, Water Resour. Res., 37, 987-998, 2001.

Zhang, X., Hegerl, G., Zwiers, F. W., and Kenyon, J.: Avoiding Inhomogeneity in Percentile-Based Indices of Temperature Extremes, J. Climate, 18, 1641-1651, 2005.

Zhang, X., Alexander, L., Hegerl, G. C., Jones, P., Tank, A. K., Peterson, T. C., Trewin, B., and Zwiers, F. W.: Indices for monitoring changes in extremes based on daily temperature and precipitation data, Wires. Clim. Change, 2, 851-870, 2011. 